\title{
Assessment of the pelagic fish populations using CEN multi-mesh gillnets: consequences for the characterization of the fish communities
}

\author{
C. Deceliere-Vergès ${ }^{(1,2)}$ and J. Guillard ${ }^{(2)}$
}

Received August 22, 2008 / Reçu le 22 août 2008

Revised October 29, 2008 / Révisé le 29 octobre 2008

Accepted November 18, 2008 / Accepté le 18 novembre 2008

Key-words: lake, pelagic zone, fish metric, CEN multi-mesh gillnets, Water Framework Directive

\section{ABSTRACT}

The contribution of CEN standard pelagic nets to the assessment of fish communities is tested by comparing three metrics (species composition, species abundance, and size structures) measured in accordance with the standard (i.e. using benthic nets only) to those calculated from the total effort (i.e. including pelagic nets). Hydroacoustic surveys were used simultaneously to assess fish densities in the pelagic habitat. The results show that in most cases the pelagic nets did not provide any extra information about these three metrics. However, their inclusion in the calculation of CPUE and size structures may affect the picture of the fish communities, especially in lakes containing salmonid populations. This study highlights the need to sample pelagic fish when assessing fish communities in order to determine lake quality.

\section{RÉSUMÉ}

L'évaluation des populations de poissons pélagiques par les filets multi-mailles CEN : conséquences pour la caractérisation du peuplement

\begin{abstract}
Mots-clés :
lac, zone

pélagique,

métrique

piscicole, filets

multi-mailles

CEN, Directive

cadre

européenne sur

l'eau

La contribution des filets pélagiques du standard CEN dans l'évaluation des peuplements piscicoles est testée en comparant les métriques (composition et abondance spécifiques, structures en tailles) mesurées conformément au standard (i.e. les filets benthiques seuls), à celles issues de l'effort total (i.e. incluant les filets pélagiques). L'hydroacoustique a été utilisée simultanément pour évaluer les densités de poissons dans l'habitat pélagique. Les résultats montrent que dans la plupart des cas, les filets pélagiques n'apportent pas d'informations supplémentaires sur les trois métriques. Toutefois, leur intégration dans le calcul des CPUE et des structures en tailles peut modifier l'image des peuplements notamment dans les lacs à salmonidés. Ce travail met en évidence la nécessité d'échantillonner les poissons pélagiques pour l'évaluation des peuplements en vue de définir la qualité du milieu.
\end{abstract}




\section{INTRODUCTION}

The EU Water Framework Directive (WFD) requires that the European countries achieve good ecological status of their water bodies by 2015 (2000/60/EC). To achieve this goal, the WFD requires the quality of aquatic ecosystems to be monitored using biological quality elements, including the fish fauna (2000/60/EC). Lakes are classified on the basis of ecotypes, and their deviations from high quality status must be defined using biotic variables as indicators. For fish, the metrics used are the species composition, especially type specific disturbance sensitive species, species abundances and age structures (2000/60/EC). It is crucial to obtain a reliable description of the fish communities in this context (Kubecka et al., 2008).

In recent years, Scandinavian scientists have developed and standardized a fish sampling method based on a random strategy for assessing the fish communities living in benthic and pelagic lake habitats (Appelberg et al., 1995; Appelberg, 2000). In temperate lakes, this method provides a whole-lake estimate for species occurrence, quantitative relative fish abundance, and biomass expressed as catch-per-unit-effort (CPUE), and the size structure of fish assemblages (Appelberg, 2000). It distinguishes between two types of equipment: benthic nets, which are set on the lake bottom and used to sample the benthic fish populations, and the pelagic nets, which are deployed at the deepest spot, along the water column in order to sample the pelagic fish populations (Appelberg, 2000). According to the WFD standard, pelagic nets are used only in the deepest lakes $(>10 \mathrm{~m})$, and should only be used to provide qualitative information about the fish communities (CEN, 2005).

In these deep lakes, the offshore area constitutes a wide habitat that is inhabited permanently or temporarily by certain fish species, particularly the salmonids that preferentially occupy the hypolimnion layer (Juget et al., 1995). The salmonid populations are sensitive to pollution including eutrophication, and are the first to disappear when the environmental quality deteriorates (Gerdeaux et al., 2006). Other species, such as cyprinids and percids, are less sensitive and generally distributed throughout the lake (Vasek et al., 2004; Prchalova et al., 2008), and can migrate preferentially into the pelagic zone if the water quality changes (Jeppesen et al., 2006). In view of these considerations, does the pelagic zone have to be taken into account when assessing and monitoring lake quality over time.

The aim of this study is to find out whether sampling the pelagic zone, as recommended by the CEN standard, has any impact on the characterization of the fish communities, and thus on assessing the lake quality as defined by the WFD. This study also highlights the importance of taking pelagic fish communities into consideration, particularly in the case of lakes with salmonid populations, which are characteristic of low trophic status. Hydroacoustic sampling is a widely-recognized effective tool for sampling the pelagic fish in lakes (Mehner and Schulz, 2002; Guillard et al., 2006; Winfield et al., 2007), and was used simultaneously during testfishing surveys in order to assess densities in the offshore areas. This paper looks at the three fish metrics used in the CEN standard: species composition, species abundance, and the size distribution which is related to the age structure (Gerdeaux, 2001). The contribution of pelagic nets to the assessment of the fish communities is tested by comparing the fish metrics calculated according to the CEN standard (i.e. with benthic nets only) to those obtained from the total effort (i.e. CEN standard plus pelagic nets). The pictures of the fish communities resulting from these two methods of calculation (i.e. CEN standard and total effort) are analyzed, and the consequences of sampling the pelagic habitat are discussed, particularly in light of the assemblages and abundances of fish communities.

\section{MATERIALS AND METHODS}

\section{> STUDY SITES}

Eleven lakes were sampled in 2005 and 2006. These lakes have differing morphological characteristics (Table I). This study formed part of a monitoring program, and so nutrient 


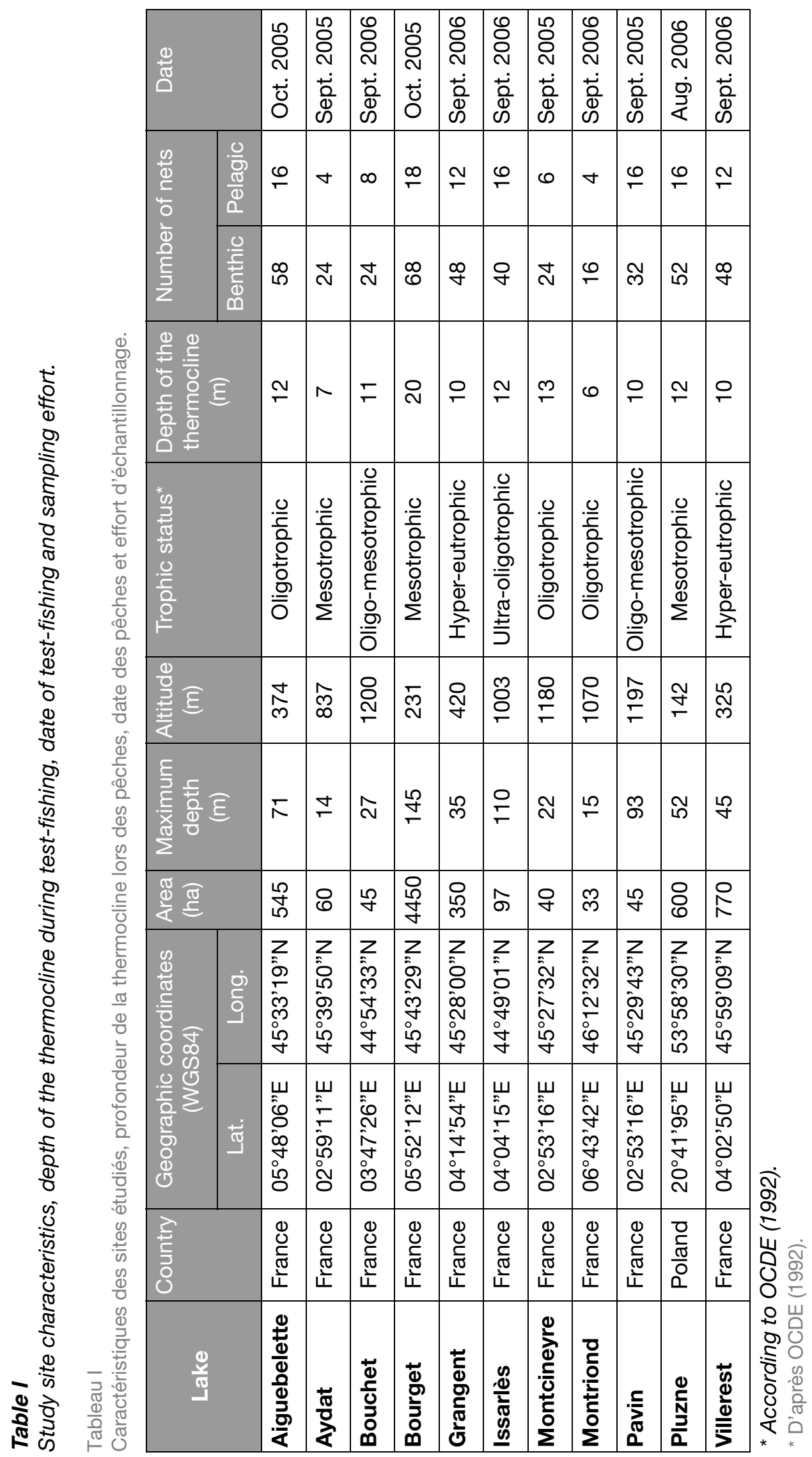


parameters were measured in order to characterize the trophic status of the lakes concerned (OCDE, 1992).

\section{$>$ METHODS}

\section{Measurements of the water temperature}

To determine the position of the thermocline, the water temperature was measured at the beginning of test-fishing in the deepest part of the lake at $1 \mathrm{~m}$ intervals from surface to bottom using a multiparametric Quanta probe (OTT Messtechnik, Austria).

\section{Gillnetting}

The samples of the benthic and pelagic habitats were carried out in accordance with the CEN standard protocol (CEN, 2005). The lakes were stratified in depth strata, and random sampling was performed within each depth stratum. The sampling effort was provided by the CEN standard, and depended on the area of the lake and its maximum depth (CEN, 2005). Two types of nets were used, the benthic nets (length $30 \mathrm{~m}$, height $1.5 \mathrm{~m} ; 2.5-\mathrm{m}$ long panels of 12 mesh-sizes with $5,6.25,8,10,12.5,15.5,19.5,24,29,35,43$ and $55 \mathrm{~mm}$; thread diameters of individual gillnet mesh sizes according to the CEN standard; Lundgrens Fiskredskapsfabrik AB, Stockholm, Sweden) were set on the bottom, and those known as pelagic nets (length $27.5 \mathrm{~m}$, height $6 \mathrm{~m}$; with 11 mesh-sizes ranging from 6.25 to $55 \mathrm{~mm}$ as given above; Lundgrens Fiskredskapsfabrik $A B$ ) set in the deepest zone. Inventories were compiled at the end of summer (Table I) according to the protocol. The nets were set before sunset, and raised after dawn, so as to include individual nycthemeral migrations, and to maximize the catchability of the fish. To be coded as a standard sampling, the netting time had to last 12 hours, and include dusk and dawn. In practice, periods of $12 \pm 1$ hours are acceptable without requiring any correction (Holmgren, pers. comm.). After being disentangled from the nets, the fish were identified to species level, weighed to the nearest gram, and their total length measured to within one millimeter. The abundances (number-perunit-effort, NPUE) and biomass (weight-per-unit-effort, WPUE) were calculated by adding the total number (or weight) of fish caught and weighting to allow for the total gillnet area set. The relative abundances and biomass of each species were weighted by the total number (or weight) of the whole sample, and then expressed as a percentage. The CPUE were calculated according to the CEN standard without weighting for the volume of depth strata, on the hypothesis that the depth strata defined by the protocol equalizes the volumes (Degerman et al., 1988; Appelberg, 2000; Lauridsen et al., 2008).

\section{Hydroacoustic surveys}

Hydroacoustic surveys were carried out to assess the pelagic fish populations, and especially the salmonids, inhabiting the hypolimnion. The echo sounder used was a Simrad EK 60, split-beam, with a frequency of $70 \mathrm{kHz}$ set for a pulse length of $0.256 \mathrm{~ms}$. The total beam angle was $11^{\circ}$ at $-3 \mathrm{~dB}$. The sounder parameters were adjusted according to the temperature to allow for the speed of sound in the water. The measurements were recorded from a 4-m length boat travelling at a mean speed of $8 \mathrm{~km} \cdot \mathrm{h}^{-1}$, the transducer being attached to the side of the boat on a pole at a depth of $0.5 \mathrm{~m}$. Sampling surveys were conducted at night in order to sample the fish while they were as widely dispersed as possible, and according to a transect strategy, except for lakes Pluzne, Villerest and Grangent, where a zigzag sampling design was used (Simmonds and MacLennan, 2005). The use of these two sampling strategies did not affect the biomass estimates as long as the cover ratio was high enough (Guillard and Vergès, 2007). The sounder was calibrated once a year in a pool (100 m long and $25 \mathrm{~m}$ deep at IFREMER, Brest), and in situ before each survey using the standard protocol of Foote et al. (1987). The detection thresholds were fixed 
at $-55 \mathrm{~dB}$ for echo integration $(20 \log \mathrm{R})$. These levels were chosen for both acquisitions and readings as it avoided interference from ambient noises and non-fish organisms, but still took into account the young fish of the year (Rudstam et al., 2002). The biomass of fish detected per unit area was calculated using the "Area backscattering coefficient" (Sa, $\mathrm{m}^{2} \cdot \mathrm{ha}^{-1}$ ) as defined by MacLennan et al. (2002), using the Sonar5-pro (Balk and Lindem, 2006). The Sa was calculated for the layer below the thermocline. The arithmetic mean was chosen, as this was thought to provide a bias-free estimator of the mean value for the zone if the effort was uniformly distributed without any initial statistical hypothesis (Smith, 1990; Guillard and Vergès, 2007).

\section{> DATA ANALYSIS}

For the species composition metric, the contribution of the two types of net was analyzed, as well as the total number of salmonid species. The $\log _{10}(C P U E+1)$-transformation of the observations was used to make the distribution of CPUE close to normal (Degerman et al., 1988; Holmgren, 1999). The contribution of the pelagic catches to the calculation of abundance and biomass was tested by comparing the mean NPUE and WPUE values obtained using the CEN standard to those obtained from the total fishing effort by using Student's t-test with a 0.05 significance level. This calculation was done for the dominant species (the four species that are present in most lakes), for the other species (by pooling the number (or weight) of each species), and for salmonids. In addition, the relative abundances found by the CEN standard and total effort were compared for salmonid species. For size distributions, the impact of including the pelagic nets was tested by comparing the metric found using the CEN standard to that obtained using the total effort, when the pelagic catch constituted more than $5 \%$ of the total catch. The size distributions were compared for the dominant species and the major salmonid species using the non-parametric Friedman exact permutation test. All statistical analyses were performed using the $R$ software (R Development Core Team version 2.2.1, 2005-12-20).

\section{RESULTS}

The fish communities were composed mostly of cyprinids, predominantly roach (Rutilus rutilus) (found in $>90 \%$ of the lakes, and on average accounting for $33 \%$ of the total relative abundance) and bream (Abramis brama) (found in $>54 \%$ of the lakes, and on average accounting for $10 \%$ of total relative abundance), and also percids, predominantly perch (Perca fluviatilis) (found in $>90 \%$ of the lakes and on average $29 \%$ of total relative abundance), and ruffe (Gymnocephalus cernuus) (present in $50 \%$ of the lakes and on average accounting for $5 \%$ of total relative abundance). Salmonid populations were present in seven lakes. For each lake, the benthic and pelagic net catches, expressed in NPUE and WPUE, are presented in Table II for the major fish families: cyprinids, percids, salmonids and others. The measurements of the acoustic biomass $\left(\mathrm{Sa}, \mathrm{m}^{2} \cdot \mathrm{ha}^{-1}\right)$ showed that among the lakes with salmonid populations, Lake Pluzne had the highest biomass, followed by lakes Pavin and Aiguebelette.

\section{> SPECIES COMPOSITION}

The contributions of the benthic and the pelagic nets to the total number of species, and to the number of salmonids provided by the CEN standard showed that the species composition was fully covered by the benthic nets, since no new species were caught in the pelagic nets, even when salmonids were present (Table III).

\section{> SPECIES ABUNDANCES AND BIOMASS}

The mean species abundance and biomass were not significantly different when determined on the basis of the CEN standard or on that of the total effort (Student test, $P>0.05$ ) 


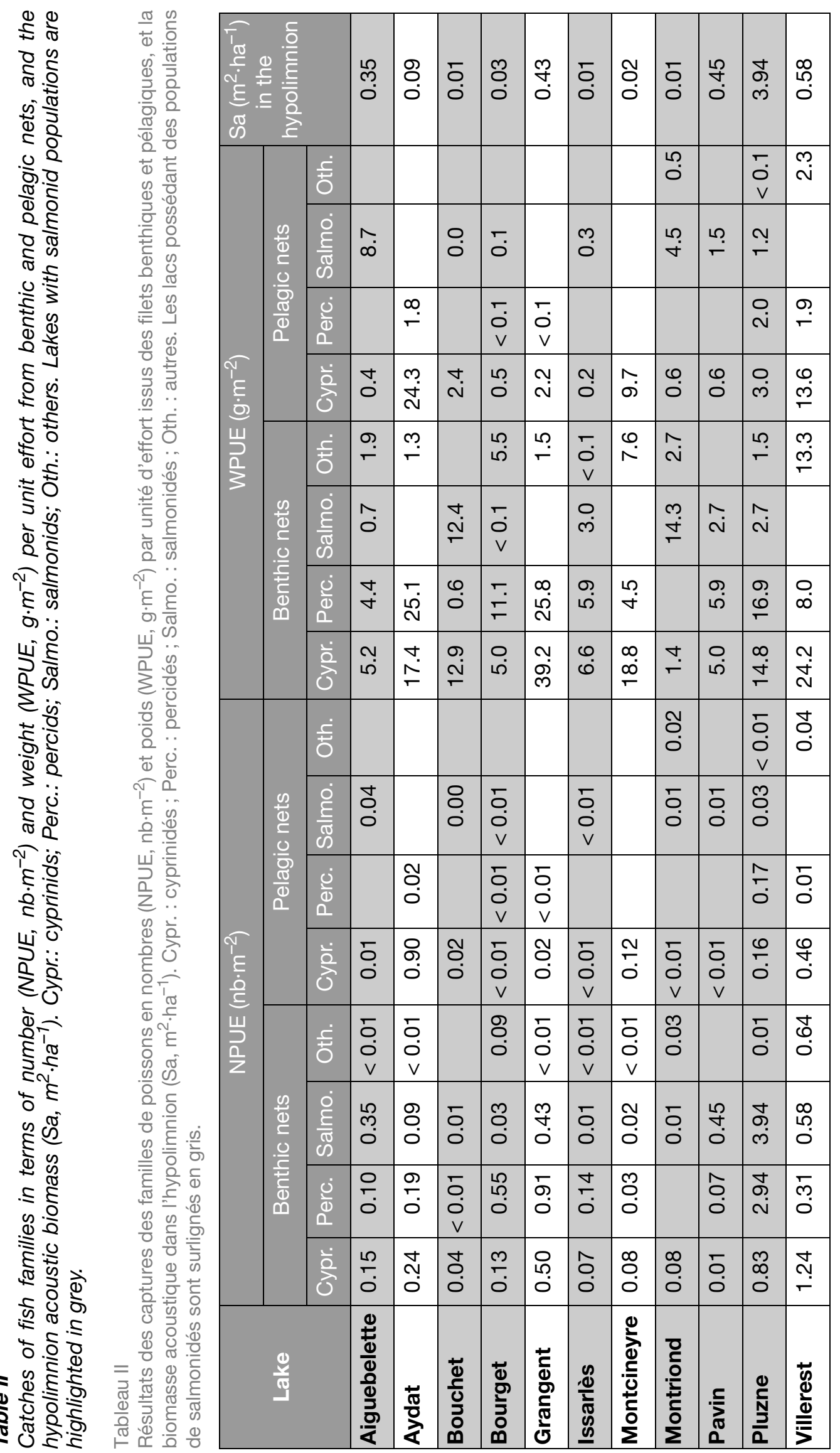




\section{Table III}

Contribution of the benthic and pelagic nets to the total number of species and number of salmonid species caught using the CEN standard. Lakes with salmonid populations are highlighted in grey.

\section{Tableau III}

Contribution des filets benthiques et pélagiques dans le nombre d'espèces totales et de salmonidés capturés à partir du standard CEN. Les lacs possédant des populations de salmonidés sont surlignés en gris.

\begin{tabular}{|c|c|c|c|c|c|c|}
\hline \multirow{2}{*}{ Lake } & \multicolumn{3}{|c|}{$\begin{array}{l}\text { Total number of fish } \\
\text { species caught }\end{array}$} & \multicolumn{3}{|c|}{$\begin{array}{c}\text { Total number of salmonid } \\
\text { species caught }\end{array}$} \\
\hline & $\begin{array}{c}\text { CEN } \\
\text { standard }\end{array}$ & $\begin{array}{l}\text { Benthic } \\
\text { nets }\end{array}$ & $\begin{array}{l}\text { Pelagic } \\
\text { nets }\end{array}$ & $\begin{array}{l}\text { CEN } \\
\text { standard }\end{array}$ & $\begin{array}{l}\text { Benthic } \\
\text { nets }\end{array}$ & $\begin{array}{l}\text { Pelagic } \\
\text { nets }\end{array}$ \\
\hline Aiguebelette & 12 & 12 & 5 & 2 & 2 & 2 \\
\hline Aydat & 7 & 7 & 4 & - & - & - \\
\hline Bouchet & 11 & 11 & 1 & 3 & 3 & 0 \\
\hline Bourget & 13 & 13 & 3 & 2 & 2 & 1 \\
\hline Grangent & 9 & 9 & 6 & - & - & - \\
\hline Issarlès & 6 & 6 & 3 & 2 & 2 & 2 \\
\hline Montcineyre & 5 & 5 & 2 & - & - & - \\
\hline Montriond & 7 & 7 & 4 & 3 & 3 & 2 \\
\hline Pavin & 6 & 6 & 2 & 2 & 2 & 1 \\
\hline Pluzne & 12 & 12 & 9 & 2 & 2 & 2 \\
\hline Villerest & 11 & 11 & 10 & - & - & - \\
\hline
\end{tabular}

(Figure 1). Moreover, the relative rank of these species and groups of species were not modified by the method of calculation.

For the whole data set, the relative biomass of the salmonid populations were similar by the calculation based on the CEN standard, and by that which included pelagic nets in the total effort (Table IV). However in Lake Aiguebelette, whitefish (Coregonus lavaretus), which accounted for less than $3 \%$ of the total biomass in the benthic nets (ranked ninth according to the CEN standard) accounted for nearly $40 \%$ if pelagic nets were included, and as a result was the dominant species in terms of biomass (ranking first for the total effort). Numerically, whitefish went from eighth rank to third rank. The same trend was observed in Lake Pavin for arctic charr (Salvelinus alpinus), and to a lesser extent in Lake Pluzne for vendace (Coregonus albula) and in Lake Montriond for rainbow trout (Oncorhynchus mykiss).

\section{> SIZE DISTRIBUTIONS}

For the dominant species of cyprinids and percids, the size distributions were in most cases identical by the two methods of calculation, i.e. CEN standard vs. total effort (Table V). For roach, in three lakes, including pelagic nets in the characterization of this metric led to a difference, partly due to catching younger age classes (Figure 2). With regard to the salmonid populations, in two lakes the number of fish caught in both types of net was big enough to permit comparison tests (Table V). In these lakes, the distributions were the same (Friedman exact permutation test, $P>0.05$ ), which led to similar size distributions for the benthic and pelagic nets (an example of size distributions is shown for Lake Pluzne in Figure 2). However, in Lake Aiguebelette, the number of whitefish found by the CEN standard was not big 


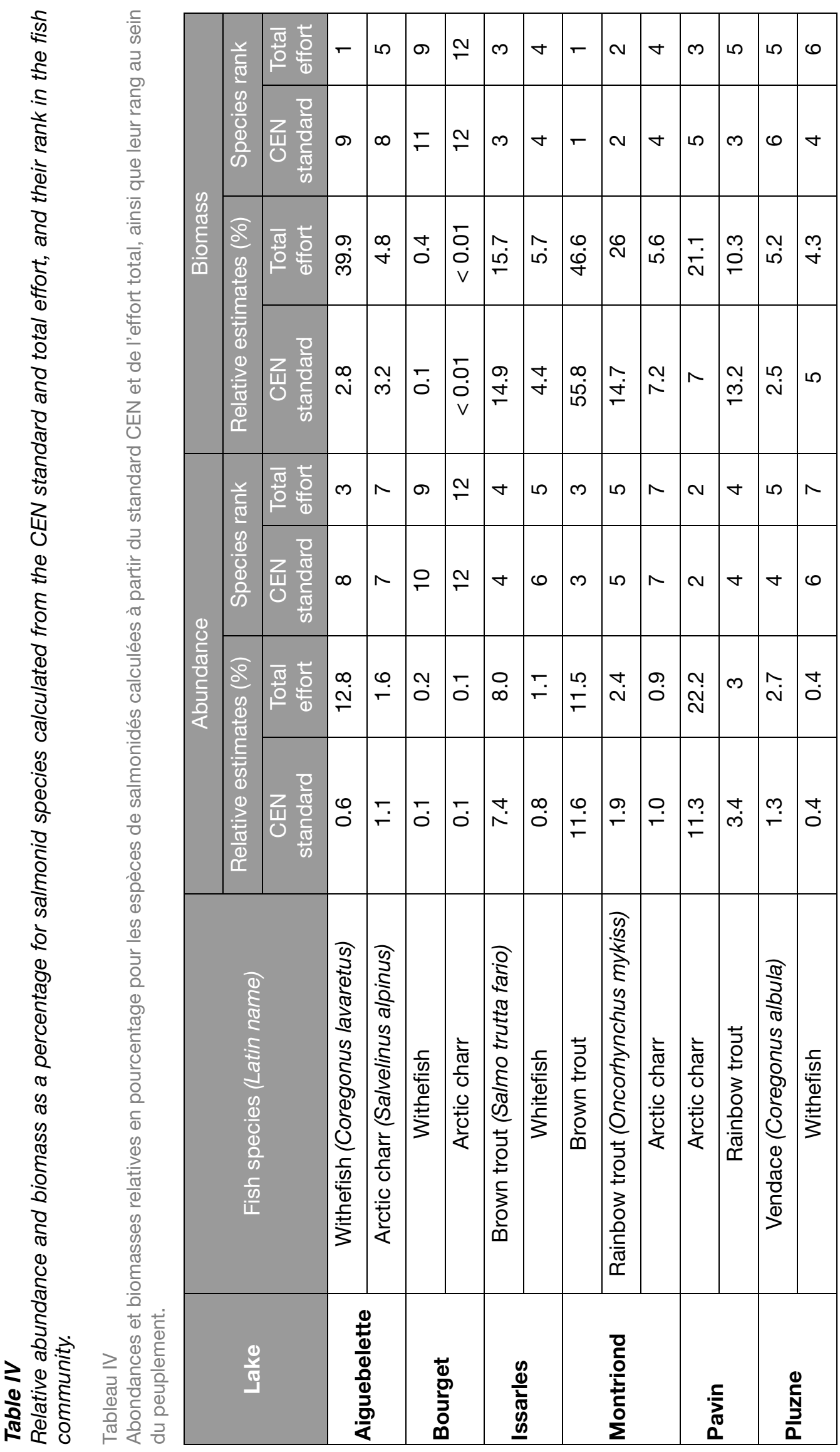




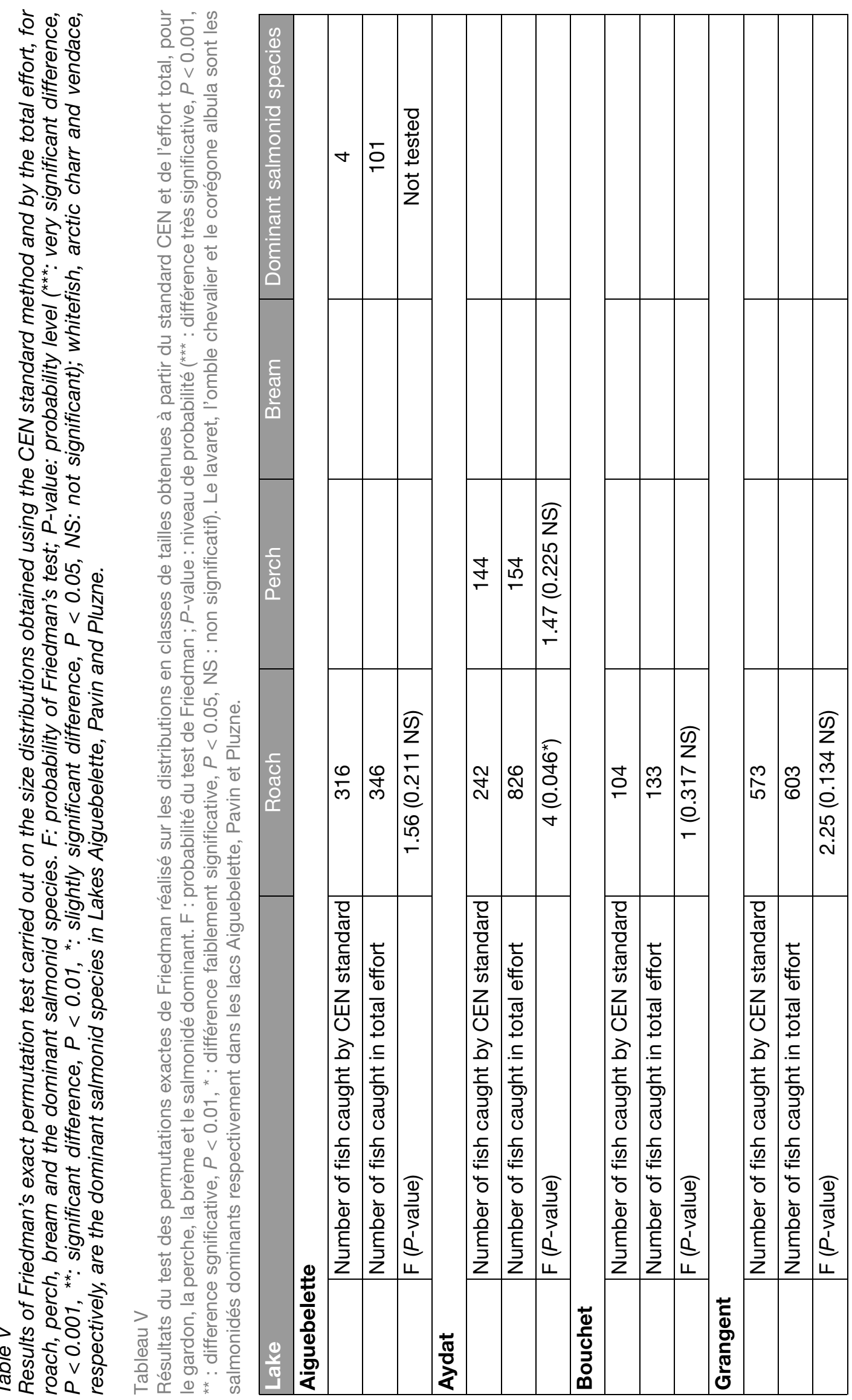




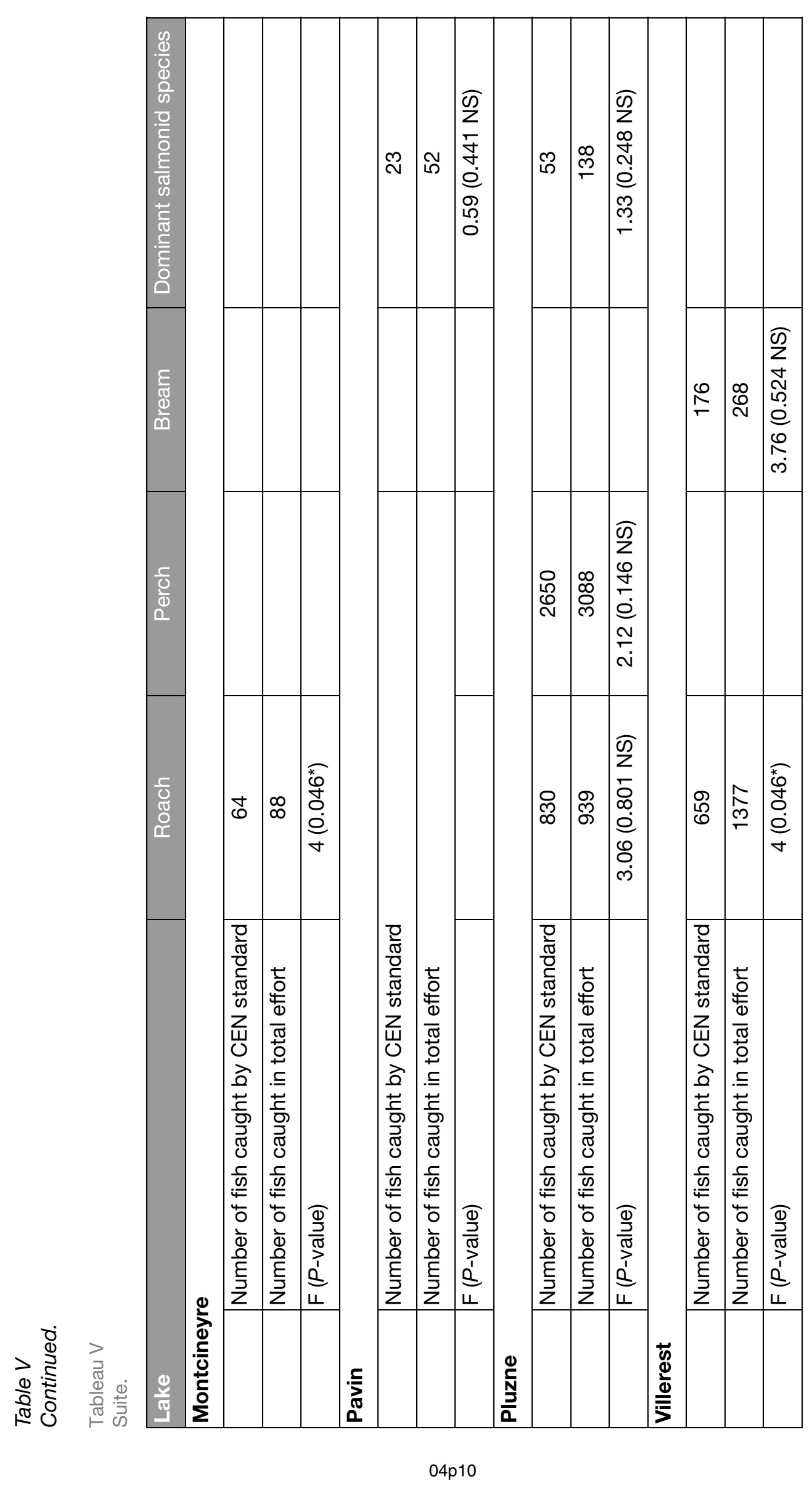




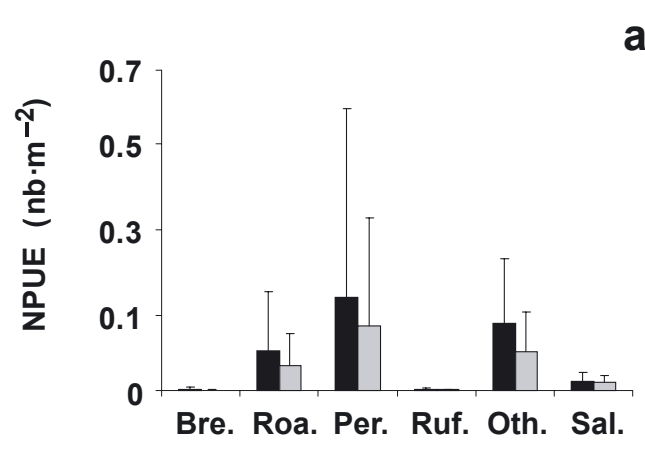

a)
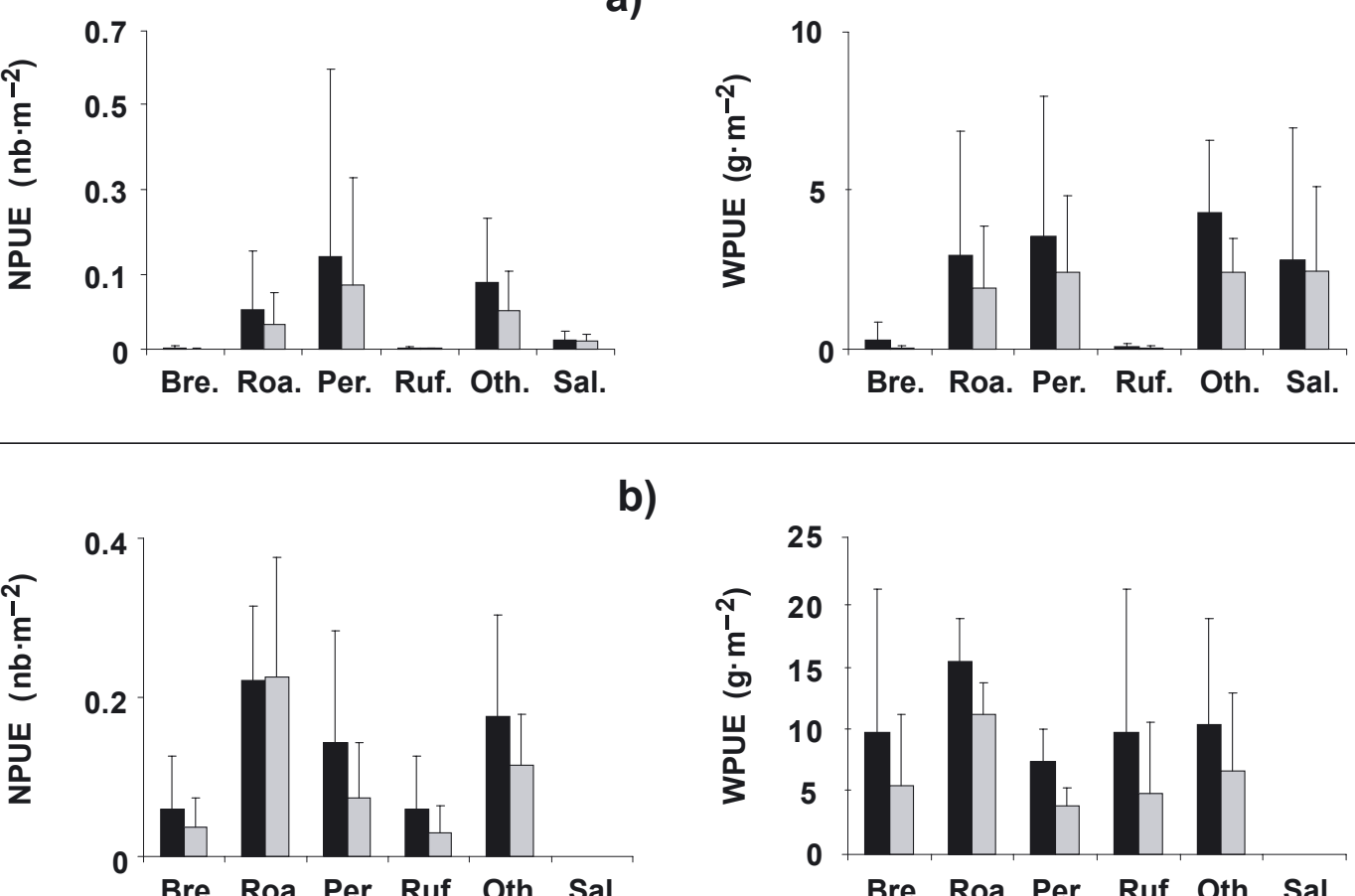

\section{Figure 1}

Mean total estimates of weight (WPUE \pm std) and numbers (NPUE \pm std) per unit effort for dominant fish species (bream, roach, perch, and ruffe), the other species, and salmonids, calculated according to the CEN standard (in black) and for the total effort (in grey). a) Lakes with salmonid populations; b) lakes without salmonid populations.

\section{Figure 1}

Moyenne des estimations totales des poids (WPUE, $\mathrm{g} \cdot \mathrm{m}^{-2}$ ) et des nombres (NPUE, $\mathrm{nb} \cdot \mathrm{m}^{-2}$ ) par unité d'effort pour les espèces dominantes (brème, gardon, perche et grémille), les autres espèces et les salmonidés, calculées à partir du standard CEN (en noir) et de l'effort total (en gris). a ) Lacs possédant des populations de salmonidés ; b) lacs sans populations de salmonidés.

enough to make it possible to calculate the size distribution, in contrast to that found from the total effort, but this example highlights the importance of the whitefish catches in the pelagic nets compared to those in the benthic nets.

\section{DISCUSSION}

The test-fishing surveys carried out in this study distinguish two types of lake, on the basis of their fish communities (i.e. those with and without salmonids) in accordance with the lake morphotypes described in the literature (Mehner et al., 2005). In both types of lake, the individual fish caught in the pelagic nets do not provide any additional information about the species composition to that provided by the benthic nets, which catch all catchable fish species. The main fish populations in these lakes (roach, bream, perch and ruffe) were caught in both types of net, due to their wide spatial distribution linked to their trophic migrations from the shoreline to the offshore area (Winfield, 2004; Jeppesen et al., 2006). In the same way, the salmonid species, which are characteristic of the pelagic zone, were in fact also caught in the benthic nets. Thus, even in a wide lake such as Lake Bourget, in which the pelagic fish community has very low abundance $\left(\mathrm{Sa}<0.05 \mathrm{~m}^{2} \cdot \mathrm{ha}^{-1}\right.$ and pelagic WPUE about $0.6 \mathrm{~g} \cdot \mathrm{m}^{-2}$ ), the benthic nets caught three whitefish and one arctic charr. 

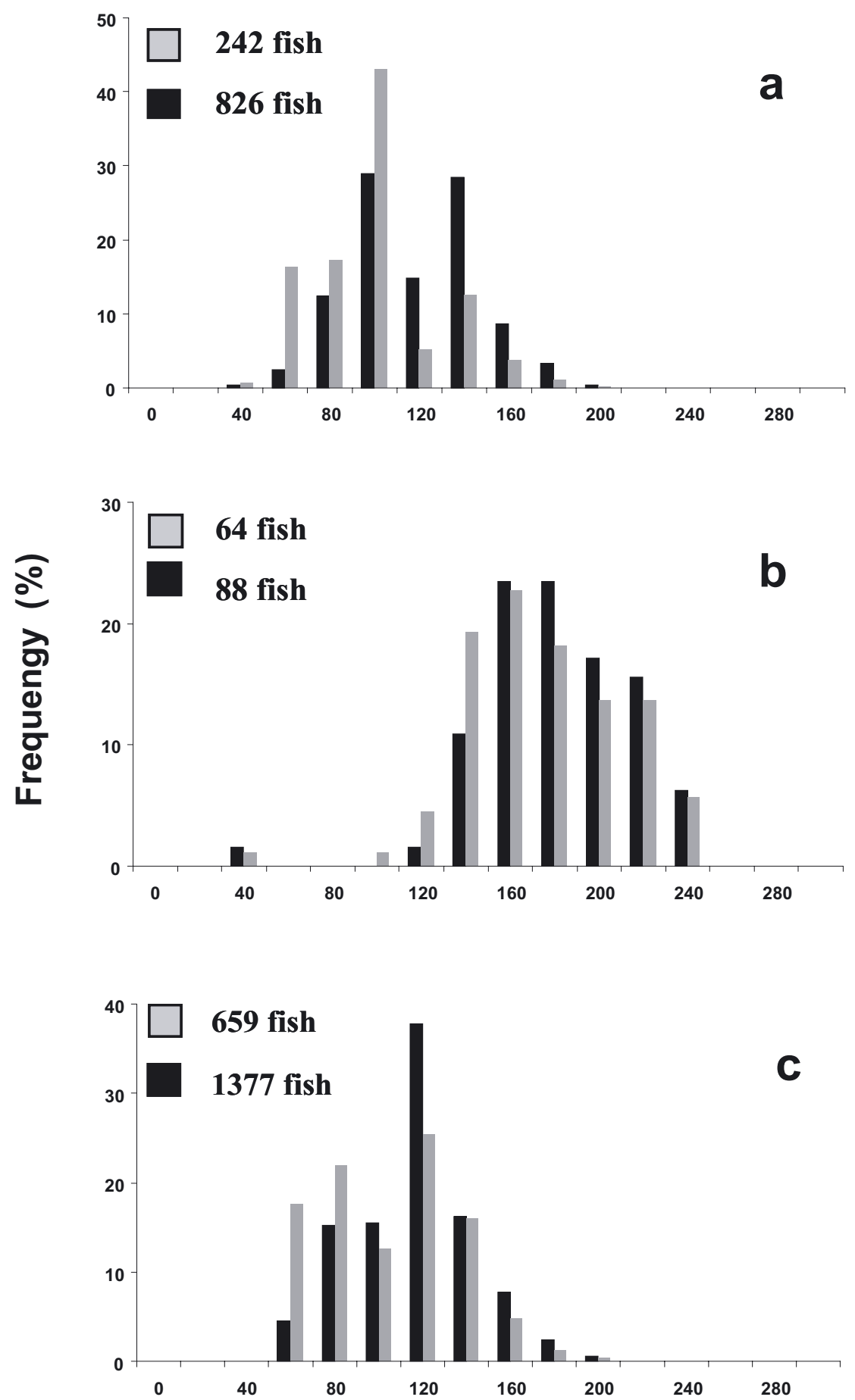

\section{Size $(\mathrm{mm})$}

\section{Figure 2}

Length-frequency distributions of roach in lakes Aydat (a), Montcineyre (b) and Villerest (c) caught using benthic nets (in grey) and in the total effort (in black).

\section{Figure 2}

Distributions en classes de taille du gardon dans les lacs Aydat (a), Montcineyre (b) et Villerest (c) capturés par les filets benthiques (en gris) et l'effort total (en noir). 
For this metric, sampling the fish fauna using only benthic nets was sufficient to evaluate the species composition, and to detect the presence of sensitive species, such as salmonids.

However, although the CEN standard provides a list of dominant catchable species, this is not an exhaustive list. Indeed, it is well known that certain species, some of patrimonial interest, are not easy to catch using gillnets because of their morphology (e.g. eel Anguilla anguilla), behavior (e.g. carp Cyprinus carpio or pike Esox lucius), or their preferred habitat in the lake (Degiorgi, 1994). Thus the littoral zone, which is inhabited by numerous fish species, provides for many of them a refuge from predators at times during their life cycle or during the diel, as well as with various trophic resources and spawning habitats (Winfield, 2004). The use of complementary sampling techniques, such as electrofishing (Jeppensen et al., 2006), would characterize the fish populations that colonize the inshore area, the presence of which is indicative of favorable living conditions, and which the CEN standard only describes partially.

In many studies dealing with lake fisheries, the CPUE resulting from gillnetting is often used as an indicator of biomass or abundance of fish populations (Yule, 2000). However, the correlation between the CPUE from gillnets and abundance based on other sampling techniques, such as active fishing gear or echo-sounding, has not always been confirmed (Hansson and Rudstam, 1995; Peltonen et al., 1999). Within the framework of lake monitoring, the definition of lake quality is based on an assessment of the relative abundances of fish species, for which the CEN standard provides an estimate through the calculation of the CPUE.

In the present study, whatever the type of lake considered, the inclusion of pelagic nets in the calculation of CPUE did not lead to a statistically significant difference from using benthic nets alone, as recommend by the CEN standard. The abundance and biomass of cyprinids and percids decreased slightly with the inclusion of pelagic nets in the calculations, but their rank within the fish community was not affected. However, modifications in environmental conditions may cause some changes in species habitat, especially in migration to the pelagic zone, and this would be detected by the pelagic nets (Diekmann et al., 2005; Jeppesen et al., 2006). Holmgren and Appelberg (2000) also stressed the importance of sampling the offshore area to take into account the pelagic obligate zooplanktivores (e.g. vendace, bleak (Alburnus alburnus) and smelt (Osmerus eperlanus)), high proportions of which within the fish communities can affect their composition as a result of the trophic interactions with omnivorous species, such as roach and perch. This emphasizes the importance of including pelagic nets in the calculation of CPUE when attempting to monitor fish populations in a comparable way over time.

When salmonids were present, the inclusion of pelagic nets might significantly affect their abundance in populations with predominantly pelagic behavior. For example, in Lake Aiguebelette including pelagic nets when calculating the abundance changed the ranking of whitefish in the total sample. However, in most lakes their contribution was not detectable, and the information provided by the pelagic nets also depended on their densities. Indeed, when the acoustic biomass was less than $0.05 \mathrm{~m}^{2} \cdot \mathrm{ha}^{-1}$, catches of salmonids in both types of net were very low, and the effect of including pelagic nets in calculating the abundance was negligible. It was also insignificant in lakes with very high acoustic biomass, such as Lake Pluzne (Sa close to $4 \mathrm{~m}^{2} \cdot \mathrm{ha}^{-1}$ ), where catches were high in both types of net. No exact relationship can be defined between hydroacoustic data and pelagic net catches, because of the small number of lakes studied, and the low sampling effort, which was too small to be reliable in the offshore area. Indeed, in the pelagic zone of deep lakes, the small sampling effort compared to the volume, constitutes a limitation of the method, which is linked to the reliability of sampling. To achieve the same degree of accuracy of the estimates of abundances as in benthic nets, Degerman et al. (1988) argue that on average 16 pelagic nets are needed per stratum instead of the two recommended by the CEN Standard. Some authors have revealed no correlation between gillnet catches and hydroacoustic data because of the catchability bias introduced by passive gears into abundance estimates (Hansson and Rudstam, 1995; Peltonen et al., 1999), particularly as the sample units were not similar over space and time. 
Moreover, in deep lakes the volume of the pelagic habitat exceeds that of the benthic habitat and fish catches determined without weighting to allow for the pelagic volume might underestimate abundance or biomass (Mehner et al., 2007). Most lakes containing salmonids are deep lakes with low productivity (Mehner et al., 2005), in which sampling of these populations requires the use of the most appropriate method, either by increasing the sampling effort in the pelagic zone, or by defining an explicit calculation of the contributions of the volumetric habitat (Lauridsen et al., 2008). The use of suitable methods, such as hydroacoustics, in large lakes and for fishery statistics may offer good alternatives and provide extra information about pelagic populations (Winfield et al., 2007; Gerdeaux and Janjua, 2008).

The size distributions of the dominant species caught in the pelagic nets were not significantly different from those of the benthic net catches, except for small pelagic roach in a few lakes, and for salmonid populations when they were predominantly pelagic, or instance whitefish in Lake Aiguebelette. The presence of these populations in the pelagic zone can be assessed better by hydroacoustic surveys, because of the selectivity bias that generally occurs with passive gears for younger fish (Mehner and Schulz, 2002; Axenrot and Hansson, 2004). For most lakes, the inclusion of the pelagic nets did not affect the characterization of the fish communities, because the number of individual fish caught in the benthic nets was high enough to define the size structures of the dominant species, as well as of salmonids.

\section{CONCLUSION}

This study shows that sampling the pelagic zone of lakes as recommended by the CEN standard does not provide any additional information about the species composition. However, including pelagic nets in the calculation of abundance, biomass and size structures is useful, especially in lakes with salmonid populations. Indeed, the failure to take the pelagic nets into account can lead to a false picture of the fish communities, impairing the definition of the lake quality as recommended by the WFD. It is necessary to extend this work to a wider range of lakes to obtain a better definition of the limits of the CEN standard in the various ecotypes specified within the framework of the WFD.

\section{ACKNOWLEDGMENTS}

We would like to thank the many people and institutions who contributed to the success of the fishing surveys particularly the staff of ASCONIT Consultants, INRA-CARRTEL, CEMAGREF, CSP, Parc Naturel Régional des volcans d'Auvergne, Fédérations de pêche, and the Polish team. This work was funded by Agence Nationale de la Recherche Technique, Agence de l'Eau, Ministère de l'Écologie et du Développement Durable and EGIDE (Polonium 2006). We are also very grateful to the two anonymous referees for their helpful comments, which considerably improved this manuscript.

\section{REFERENCES}

2000/60/EC. Directive of the European Parliament and of the Council of 23 October 2000 establishing a framework for Community action in the field of water policy. Official Journal of the European Communities L 327, 22.12.2000, 1-73

Appelberg M., 2000. Swedish standard methods for sampling freshwater fish with multi-mesh gillnets. Fiskerieverket Information, 1, 3-32. 
Appelberg M., Berger H.-M., Hesthagen T., Kleiven E., Kurkilahti M., Raitaniemi J. and Rask M., 1995. Development and intercalibration of methods in Nordic freshwater fish monitoring. Water Air Soil Pollut., 85, 401-406.

Axenrot T. and Hansson S., 2004. Seasonal dynamics in pelagic fish abundance in a Baltic Sea coastal area. Estuar. Coast. Shelf Sci., 60, 541-547.

Balk H. and Lindem T., 2006. Sonar5 post processing systems. Operator manual version 5.9.6, 411 p.

CEN, 2005. Water Quality - Sampling of Fish with Multimesh Gillnets. European Committee for Standardization, EN 14757, Brussels.

Degerman E., Nyberg P. and Appelberg M., 1988. Estimating the number of species and relative abundance of fish in oligotrophic Swedish lakes using multi-mesh gillnets. Nordic J. Freshw. Res., $64,91-100$.

Degiorgi F., 1994. Étude de l'organisation spatiale de l'ichtyofaune lacustre. Thèse de Doctorat, Université de Franche Comté, France, $191 \mathrm{p}$.

Diekmann M., Brämick U., Lemcke R. and Mehner T., 2005. Habitat-specific fishing revealed distinct indicator species in German lowland lake fish communities. J. Appl. Ecol., 42, 901-909.

Foote K.G., Knudsen H.P., Vestnes G., MacLennan D.N. and Simmonds E.J., 1987. Calibration of acoustic instruments for fish-density estimation: a practical guide. ICES Cooperative Research Report, $144 \mathrm{p}$.

Gerdeaux D., 2001. Détermination de l'âge et de la croissance des poissons. In: Gerdeaux D. (ed.), Gestion piscicole des grands plans d'eaux, INRA Paris, 215-239.

Gerdeaux D. and Janjua M.Y., 2008. Contribution of obligatory and voluntary fisheries statistics to the knowledge of whitefish population in Lake Annecy (France). Fish. Res., doi:10.1016/j.fishres.2008.09.016.

Gerdeaux D., Anneville O. and Hefti D., 2006. Fishery changes during re-oligotrophication in 11 perialpine Swiss and French lakes over the past 30 years. Acta Oecol., 30, 161-167.

Guillard J. and Vergès C., 2007. The repeatability of biomass estimates and fish size distributions by hydroacoustic surveys using different sampling strategies and statistical methods. Internat. Rev. Hydrobiol., 92, 6, 605-617.

Guillard J., Perga M.-E., Colon M. and Angeli N., 2006. Hydroacoustic assessment of young-of-year perch, Perca fluviatilis, population dynamics in an oligotrophic lake (Lake Annecy, France). Fish. Man. Ecol., 13, 319-327.

Hansson S. and Rudstam L.G., 1995. Gillnet catches as an estimate of fish abundance: a comparison between vertical catches and hydroacoustic abundances of Baltic Sea herring (Clupea harengus) and sprat (Sprattus sprattus). Can. J. Fish. Aquatic Sci., 52, 75-83.

Holmgren K., 1999. Between-year variation in community structure and biomass-size distributions of benthic lake fish communities. J. Fish Biol., 55, 535-532.

Holmgren K. and Appelberg M., 2000. Size structure of benthic freshwater fish communities in relation to environmental gradients. J. Fish Biol., 57, 1312-1330.

Jeppesen E., Pekcan-Hekim Z., Lauridsen T.L., Sondergaard M. and Jensen J.P., 2006. Habitat distribution of fish in late summer: changes along a nutrient gradient in Danish lakes. Ecol. Freshwater Fish, 15, 180-190.

Juget J., Lafont M., Mouthon J. and Gerdeaux D., 1995. Structure des communautés benthiques et pisciaires. In: Pourriot R. and Meybeck M. (eds.), Limnologie Générale, Masson Paris, 494-513.

Kubecka J., Amarasinghe U.S., Bonar S.A., Hateley J., Hickley P., Hohausová E., Matena J., Peterka J., Suuronen P., Tereschenko V., Welcomme R., Winfield I.J., 2008. The true picture of a lake or reservoir fish stock: A review of needs and progress. Fish. Res., doi:10.1016/j.fishres.2008.09.021

Lauridsen T.L., Landkildehus F., Jeppesen E., Jørgensen T.B. and Søndergaard M., 2008. A comparison of methods for calculating Catch Per Unit Effort (CPUE) of gill net catches in lakes. Fish. Res., 93, 204-211.

MacLennan D.N., Fernandes P.G. and Dalen J., 2002. A consistant approach to definitions and symbols in fisheries acoustics. ICES J. Marine Science, 59, 365-369.

Mehner T. and Schulz M., 2002. Monthly variability of hydroacoustic fish stock estimates in a deep lake and its correlation to gillnet catches. J. Fish Biol., 61, 1109-1121.

Mehner T., Diekmann M., Brämick U. and Lemcke R., 2005. Composition of fish communities in German lakes as related to lake morphology, trophic state, shore structure and human-use intensity. Freshwater Biol., 50, 70-85. 
Mehner T., Holmgren K, Lauridsen T.L., Jeppesen E. and Diekmann M., 2007. Lake depth and geographical position modify lake fish assemblages of the European Central Plains ecoregion. Freshw. Biol., 52, 2285-2297.

OCDE, 1982. Eutrophisation des eaux. Méthodes de surveillance, d'évaluation et de lutte. Organisation de Coopération et de Développement Économiques (OCDE), Paris, 164 p.

Peltonen H., Ruuhijärvi J., Malinen T. and Horppila J., 1999. Estimation of roach (Rutilus rutilus L.) and smelt (Osmerus eperlanus L.) stocks with virtual population analysis, hydroacoustics and gillnet CPUE. Fish. Res., 44, 25-36.

Prchalova M., Kubecka J., Vasek M., Peterka J., Sed'a J., Juza T., Riha M., Jarolim O., Tuser M., Kratochvil M., Čech M., Drastik V., Frouzova J. and Hohausova E., 2008. Distribution patterns of fishes in a canyon-shaped reservoir. J. Fish Biol., 73, 54-78.

Rudstam L.G., Van De Valk A.J. and Scheuerell M.D., 2002. Comparison of acoustic Miller high-speed sampler estimates of larval fish abundance in Oneida Lake, New York. Fish. Res., 57, 145-154.

Simmonds E.J. and MacLennan D.N., 2005. Fisheries Acoustics: Theory and Practice. Oxford: Blackwell Science Ltd., 437 p.

Smith S., 1990. Use of statistical models for the estimation of abundance from groundfish survey data. Can. J. Fish. Aquatic Sci., 47, 894-903.

Vasek M., Kubecka J., Peterka J., Čech M., Drastik V., Hladik M., Prchalova M. and Frouzova J., 2004. Longitudinal and vertical spatial gradients in the distribution of fish within a canyon-shaped reservoir. Internat. Rev. Hydrobiol., 89, 4, 352-362.

Winfield I.J., 2004. Fish in the littoral zone: ecology, threats and management. Limnologica, 34, $124-131$.

Winfield I.J., Fletcher J.M. and James J.B., 2007. Seasonal variability in the abundance of Arctic charr (Salvelinus alpinus (L.)) recorded using hydroacoustics in Windermere, UK and its implications for survey design. Ecol. Freshwater Fish, 16, 64-69.

Yule D.L., 2000. Comparison of horizontal acoustic and purse-seine estimates of salmonid densities and sizes in eleven Wyoming waters. N. Am. J. Fish. Manag., 20, 759-775. 